\title{
Chapter 7 \\ Research, Innovation, Indigenous \\ Knowledge and Policy Action in Africa
}

\section{Introduction}

Innovation, invention and creativity are the major drivers of growth and advancement in nations across the globe. A country that invests in creating an enabling environment for its human capital to operate at optimum usually receives yields by way of highly innovative products and services. At the foundation of innovation and invention is knowledge-intimate knowledge of the environment within which the end product will be utilized. Indigenous knowledge forms the basic foundation of knowledge for much of Africa's population south of the Sahara. Conversely, rather than ideally forming the foundations for teaching and research across the region, this variant of knowledge has been marginalized from formal learning and research platforms. As stated elsewhere in this volume, this state of affairs is traceable to the colonial origins of formal education and research in Africa, and the continued dependence on external forces for education funding (Brock-Utne 2000). He who pays the piper dictates the tune, and therefore, rather than an emphasis placed on Africa's indigenous knowledge in curriculum and in research focus areas, western curriculum and western agenda usually form the basis. Research for development in Africa must not only be relevant to the needs of the people concerned and be appropriate to the social and material environments in which it is pursued (Hanushek and Ludger 2007), it must also be adaptive and cumulative - that is, responding to the exigencies of situations and be meaningful to the members of the society, taking into account their aspirations and concepts of development. In his 1999 Development as Freedom, Amartya Sen, opines that real development occurs when a people are free to define their development based on societal dynamics. This view is also presented in many other variants by numerous scholars writing on education and societal advancement (see Dewey 1959; Freire 1972; Brock-Utne 2000). This chapter explores the question of whether the incorporation of Africa's indigenous knowledge into the continent's research and development process will not offer more viable approaches to its innovation and creativity across the region. Along that line, the chapter seeks to explore 
any connection between the low level of innovation and inventions in Africa and the absence of indigenous knowledge in teaching, learning, and research across the continent. It starts by exploring the fundamental tenets of innovation and then proceeds to look at the relationship between innovation and indigenous knowledge by drawing examples from regions outside of Africa. The paper further explores options for mainstreaming indigenous knowledge in policy making across the continent, and concludes with the assertion that an emphasis on indigenous knowledge is crucial in African governments' efforts at creating a crop of highly innovative and creative citizenry.

\section{Innovation}

Innovation generally entails the idea of doing new things. It is the whole process of renewing, changing, transforming, or indeed creating more efficient and effective means, products, processes, or ways of doing things. There is widespread convergence around the fact that innovation is a major source of organizational or national wealth, health, and overall advancement (West 2000; Drucker 1992). It has been said that innovation rules the world; nations that are constantly innovative have been shown to grow at a much higher rate than nations that are only rich in mineral, human, or any other resources, but lacking in the innovation edge (OECD 2000). A good example is the United States, where it was assumed for over 200 years that economic growth came about as a result of increased input of capital and labor in production processes, thereby resulting in greater output. It was not until Robert Solow, who would later win a Nobel Prize in Economics for his work, established that only $15 \%$ of economic growth in the United States between 1870 and 1950 occurred as a result of increased input of labor and capital (Rosenberg 2004). That is, between 1870 and 1950, increased input of capital and labor "could only account for about $15 \%$ of the actual growth in the output of the economy. In a statistical sense, then, there was an unexplained residual of no less than 85\%" (Rosenberg 2004). It was the unexplained residual of $85 \%$ that "persuaded most economists that technological innovation must have been a major force in the growth of output in highly industrialized economies" (Rosenberg 2004).

Today, innovation in science and technology remain a major force in determining the rate of economic growth recorded by nations. Nesta, the United Kingdom's innovation foundation, conducted a study, which established that between 2000 and $2008,63 \%$ of the growth rate recorded in the United Kingdom could be attributed to innovation, while only about $37 \%$ could be linked to more inputs of capital and labor (Nesta Foundation 2013). According to the Foundation, "research, the ability to turn ideas into useful new products, services and ways of doing things is the wellspring of prosperity for any developed country" (Rosenberg 2004). Source-(Nesta Foundation 2013) 


\section{Appropriate Technology for Innovation}

Technology implies the application of scientific knowledge. The process of applying scientific knowledge to address real-life issues often occurs through invention, innovation or the creation of a new product or method (Gordon and Waage 2010). Technological innovation is at the bedrock of the quest for improved economic growth in most nations across the globe. This technological innovation is often the result of intentional, consistent and sustained investments in appropriate industrial and technological research by governments and private sector (Grossman 1993).

If investment in appropriate technology is a key to innovation, it is important to understand the concept of appropriate technology. For technology to be considered appropriate it must be founded on certain fundamental principles, which include

- Accessibility and affordability-this means that instruments needed for innovation to occur must be accessible and easily afforded by majority of the population expected to engage in innovative practices. The situation where technology depends on imported parts or expertise to both take-off and be sustained does not fall within what can be termed appropriate technology.

- Ease of utilization and maintenance-technology created within a locale must be easy to use and be maintained by the members of the community or some designated experts among them. If technology is hard to understand and difficult to maintain by community members, then that technology is not appropriate.

- Meeting real needs of end-users-meeting the real and not the imagined or superimposed needs of end-users should be the guiding principle in innovation that is based on appropriate technology.

- Effectiveness

Innovation in the fields of technology, therefore, should have the aforementioned attributes. The implication is that there is the need for a deep knowledge of the environment where the product being developed is to be utilized. Researchers, inventors, and innovators who have an intimate understanding of their environment are often more succeessful in developing needful technology or other products, tangible, and intangible, which impact the environment in deep and meaningful ways, oftentimes bringing about transformation and noticeable progress.

\section{A Case for Localized Innovation}

In a groundbreaking theory, Basu and Weil (1998) proposed that localized innovation is a strong and driving force in economic growth. According to the theory, new knowledge, although relevant for increased technological production can only be applicable or appropriate when used in those "countries that produce according to technologies similar to the innovator's technology" (Los andTimmer 2003). The 
implication is that when a product is developed in a particular environment, the innovation needed to develop its offshoots is more likely to be generated in the same environment where the original product was created. In essence, the idea of transferring technology is not sustainable since it is highly unlikely that imported technology will easily take root in a foreign environment and form a basis for more innovation in its new territory. It is in this regard that appropriate technology needs to be situated in the preexisting technological knowledge or environmental reality of the innovator. This is where indigenous knowledge comes to the fore.

\section{Indigenous Knowledge and Innovation}

Innovation is often a product of in-depth knowledge and expertise in a particular field. People who are well versed in indigenous knowledge and who also understand their environment intimately are more disposed to being inventors and being innovative, if the right kind of support and access to information are made available.

Although technology transfer has assisted Africa in some way, it has, however, consistently proven to not be what can launch the continent into the level of advancement it needs. Local community members are often lacking in appropriate knowledge regarding the maintenance of imported technology, Africans, therefore, remain dependent on importation. On the other hand, indigenous technologies have been developed and utilized over an extended period in Africa. It has been tried and tested within local communities and has proven to meet the immediate needs of the people. Examples include natural medicine, agricultural techniques, governance mechanisms, etc. As a matter of fact, indigenous knowledge is known to have laid the foundation for quite a few of what is considered modern knowledge or technology. In the United Kingdom, the efforts of Evan Thomas, a traditional bonesetter of enormous talent and training, based in Liverpool whose satisfied clients included Prime Minister William Gladstone, transformed the field of traditional bonesetting to modern orthopaedic medicine (Green 1999).

In China, the establishment of university level education in orthopaedic medicine, at the initial stages, copied the curriculum available in the Western universities. But it was not long before Chinese-trained orthopaedic medical practitioners opened up to indigenous knowledge of Chinese traditional bonesetters. These westernized trained medical doctors have been able to redesign and remodify given assumptions inherited from the west, through their interaction with the knowledge of Chinese traditional bonesetters (Shang and Dong 1987). An example is the traditional bonesetter's superior treatment of displaced bone fractures of the forearm. The western method of dual plating was displaced by the bamboo splint method used by China's traditional bonesetters (Fang, Ku, and Shang 1996). In Turkey, the knowledge of Turkish traditional bonesetters is valued in modern orthopaedic medicine research and practice (Atici and Atici 2004, 50). 


\section{Indigenous Knowledge and Research in Africa}

There is an obvious disconnect between what is generally researched in Africa and what the real needs of the majority of Africans are. Woodman and Bradford (1987) observed that it has proven difficult to design workable development strategies in Africa due to the fact that the region's contemporary approach to development is a complete deviation from the knowledge, principles, and values of the indigenous communities over which the colonially contrived nation states have imposed their rule. Education is the surest and quickest path to ensuring social continuity and bringing about transformation in any society. For Dewey, human beings "are born not only unaware of, but quite indifferent to, the aims and habits of the social group and have to be rendered cognizant of them and made to become actively interested; education and education alone, spans the gap" (Dewey 1959, p. 3). Education ought to be based on the real-life experiences of learners and what their immediate environment and social realities entail. In this instance any "rift between curriculum and society must be bridged" (Walker and Jonas 1986, p. 11).

The World Bank's admits that "educational research has shown that teaching supported with prior knowledge increases students' ability to grasp materials taught to them (...) and they are more apt to retain information." (World Bank 2000) The document further advises educators to utilize indigenous knowledge as the basis to "build on and teach new concepts" a process known as constructivist learning." In sub-Saharan Africa, education and research has mostly taken the form of an outside -in approach whereby the agenda for what is to be researched is set by the donors or development partners. This is also the case with curriculum of teaching and learning. Very few efforts, transformative in approach and content, has been put into modifying the curricula of teaching and learning across the continent of Africa, in order to make for independent, environmentally generated and sensitive teaching, learning and research.

Research that will lead to advancement in Africa will have to be founded on appropriate education. Classroom content must integrate "particular curriculum content and design, instructional strategies and techniques, and forms of evaluation" (Trifonas 2003, p. 23). In Africa, research agenda, curriculum and "given" conceptual frameworks should be continuously reexamined by researchers, teachers and students, with the aim of eschewing all manifestations of neo-colonial underpinnings and emphasizing indigenous ideas and addressing Africa's peculiar realities and challenges (Ezeanya 2011).

In the search for knowledge within any particular community, people's history, culture, and worldview ought to form the baseline for further studies and analysis (Sarpong 2002). Africa is rich with indigenous knowledge in all fields and sectors, which the advent of Western methods of scientific inquiry repudiated. The result of this disregard for what is authentically African in agriculture, science, mathematics, geography, arts, medicine, politics, economics, to mention few, is a detachment of research from the people's lived experiences. African researchers struggle for relevance and to have the masses appreciate their research output, but this has proven 
difficult over the years as a result of the disconnect that exists between research and reality. According to Mkabela, "it is the examination of the African reality from the perspective of the African; one that places the African experience at the core, recognizes the African voice and reaffirms the centrality of cultural experience as the place to begin to create a dynamic multicultural approach to research" (Mkabela 2005). It is very important, therefore, for African researchers to reacquaint themselves with Africa's knowledge systems and research.

There is need for African researchers to establish a foundation of learning that is in indigenous knowledge. Western and other acquired knowledge, skills, methodologies and tools of research will form part of the structure of education in Africa, but not the basis, as is presently the case (Nsamenang 1995). In essence, Western solutions and research strategies for discovering new knowledge are not made to measure for all. The West does not hold the key to research methodology and approaches for understanding the rest of the world. In Africa, the lack of emphasis on this truth has brought about distortions in efforts towards advancing the continent and its people. According to UNESCO, "new insights reveal that development interventions have failed to induce people to participate because of the absence of instruments and mechanisms that enable them to use their own knowledge. Greater efforts therefore should be undertaken to strengthen the capacity of local people to develop their own knowledge base and to develop methodologies to promote activities at the interface of scientific disciplines and indigenous knowledge" (UNESCO 2000) African researchers are reluctant to tackle challenges facing the continent unless they are to be funded or to enter into some sort of partnership with Western institutions. These are hindrances to authentic research works in Africa and the production of authentic knowledge out of the continent.

\section{Mainstreaming Indigenous Knowledge in Policy Action}

Policy backing and support is fundamental in ensuring that appropriate technology is emphasized across national boundaries, which will in turn foster innovation across Africa. Public policy used here refers to the activities, or lack of it, pursued by government officials and their agencies in trying to address issues of public interest. Public policy is crucial in the drive towards the political, social, and economic advancement of any nation. Economic policy decisions can strongly encourage the utilization of appropriate technologies within institutions and across sectors, leading to periods of national economic growth.

Policy formulation, to be effective, must be preceded by the appropriate identification of challenges, but what drives results is the determination to, as much as possible, draw, or locate solutions within the ambient environment and not from externally induced or copied modalities. Oluba (2010) opines that appropriate policy must be theoretically sound and be logically consistent and sustainable, in addition to being backed by appropriate laws that are widely accepted by the general public. What this implies is that public policy must essentially be in direct response to 
local challenges, using locally relevant ideas and processes. It is very important that public policy be relevant within the context of its implementation. Ndah $(2010,5)$ states that "government decisions and actions become ineffective when they fail to address public problems in ways that are consistent with widely shared values and preferences."

For much of sub-Saharan Africa's recent history, however, public policy declarations, although emanating from the lips of African leaders, have often been formulated on their behalf by external parties, and/or copied from other nations. Much of sub-Saharan African states are yet to take up the challenge of authentic public policy formulation and implementation based on indigenous knowledge. There is still an over-reliance on external "experts" to construct governance mechanisms and processes across the region (Mkandawire and Soludo 1999). Africa's long years of inappropriate policy making have been established as one of the major reasons for the continent's persisting development challenge (Olokoshi 2000), since ill-fitting policies lead to ill-developed nations.

Decades after colonialism, the end of Cold War, and with the public acknowledgement of the ill-effects of the Structural Adjustment Program, African countries have allowed the aid industry and a lack of political will to continue to dictate the tune of public policy. Although there has been some noticeable progress, public policy formulation and implementation in Africa still relies very much on the counsel and examples of outsiders than on being generated from authentic local realities in order to address local challenges. Indeed, Africa's previous attempts at nation building has more often than not, relied on externally dug foundations, but while the assistance of outsiders might in several instances prove invaluable, its role must be restricted to a supportive, rather than a transformative role (Birdsall 2005). Development strategies, to be effective, must be decided and crafted within the area where the development is to take place. The inappropriateness that is characteristic of Africa's recent public policy history is not without a background. Precolonial African societies were known to have fashioned public policy in accordance with local realities. Such policies or rules and regulations addressed the needs of the population and were generally understood by all. Governments in most precolonial African societies emphasized self-reliance. The social, political and economic independence of nations was of paramount importance to leadership, as such, there was no question of yielding public policy and decision making to external forces (Kisangani 2005). Such principles as accountability, transparency, and rule of law have been liberally identified as being very much present in several precolonial governance systems (Ezeanya 2014).

Owusu (2012, p. 137) avers that "colonial governments in many countries did not develop the capacity of the state; rather they established only the minimum state and bureaucratic capacity to help maintain law and order and facilitate resource extraction." Public policy making would then shift from an independent and growth centered enterprise with adequate and well trained personnel, to one where untrained or ill-trained personnel were hired to depend on external forces for directions and strategy. 
For several reasons, in a post-independence Africa, leaders felt incapacitated by way of fashioning policies rooted in authentic African realities. Outside of such founding fathers as Julius Nyerere of Tanzania, Kwame Nkrumah of Ghana and a few others who made efforts towards authentic policy action, much of immediate postIndependence policy making depended on external parties. The Cold War division of the continent along ideological lines did not tolerate much originality in decision making across government officials in Africa. That ideologically charged era fed into the era of Structural Adjustment Program (SAP) for much of the continent.

Under SAP, African governments were told in no uncertain terms to follow a policy formula pre-fabricated in the Bretton Woods offices in Washington D.C. Erring governments were threatened with economic sanctions of doomsday proportions and there were few who did not toe the line. SAP fed into the era of foreign aid; donor funded and often times, donor determined policy took root across Africa. The aid business blossomed at an unprecedented rate across the region. In and out of Africa flew consultants from the Eastern and Western hemisphere, clutching suitcases with one hand, and briefcase filled with policy documents with the other, crafted and ready to be handed over for implementation to African governments. Few African governments saw the need, and were convinced of having the capacity to search out and implement grassroots and homegrown or indigenous knowledge based public policy across sectors. A recognition of the inherent inability of western knowledge to form the foundation of advancement across Africa is a first step towards fashioning policies that will strengthen research on indigenous knowledge, which will in turn ensure a highly innovative Africa.

\section{Conclusion}

Despite decades of graduating university and post graduate students in Africa, there has been recorded a low level of innovation and invention across the region. The persistence of several developmental challenges and the snail speed drive towards technological advancement across Africa points to foundational issues with the region's research and development agenda. Africa, for instance, records the lowest patent applications around the world and begs the question, how are the existing curriculum and research agenda contributing to the dearth of widespread innovation and inventions across the continent? Inventions, innovation, and creativity spring from a place of familiarity and spontaneity. Indigenous knowledge is the knowledge that many Africans are acquainted with, but it is not incorporated in teaching curricula and research agenda across the continent. Research for the average African researcher is an enigma that can only be unwrapped with funding, assistance or publication platforms offered outside of the continent's realities. Rich and potentially life-transforming indigenous knowledge in certain fields explored in this volume, such as agriculture, environment, pharmacology, and mathematics, if incorporated as part of the teaching curriculum and a foundational part of research agenda in 
Africa, will most likely result in a remarkable increase in innovation and creativity across the region. To work effectively with indigenous knowledge, researchers would have to be a little more humble, patient, determined, sensitive, flexible, creative, unconventional, open-minded, critical, and cautious.

Empowering indigenous knowledge as a fundamental aspect of research in Africa will make for spontaneity which has been identified as the bedrock of creativity and innovation. Ease of access to research materials will be another major reason for innovation and creativity thriving in Africa when indigenous knowledge is given emphasis. Transformative homegrown and grassroots based creativity and innovation across all sectors, including trade and economics, philosophy, science and technology, the creative arts, politics, social and cultural, and others, will be experienced when Africa's indigenous knowledge is accorded its place in research.

\section{References}

Ahyi G (1997) Traditional models of mental health and illness in Benin. In: Hountondji P (ed) Endogenous knowledge: research trials. CODESRIA, Dakar

Atici E, Atici T (2004) The development of orthopaedics and traumatology in Turkey and some results. JISHIM (3):50-55

Basu S, Weil D (1998) Appropriate technology and growth. Q J Econ 113(4):1025-1054

Birdsall R (2005) How to help poor countries. Foreign Affairs, pp. 136-152

Brock-Utne B (2000) Whose education for all: the recolonization of the African mind. Falmers Press, New York

Dewey J (1959) Moral principles and education. Philosophical Library, New York

Drucker P (1992) Managing for the future. Butterworth-Heinemann, Oxford, England

Ezeanya C (2011) Education and Indigenous knowledge in Africa: traditional bonesetting and orthopaedic medicine in West Africa. Washington D.C.: Howard University

Ezeanya C (2014) Corruption and Citizenship in sub-Saharan Africa: a historical analysis. In: Mudacumura G, Morcol G (eds) Challenges to democratic governance in developing countries. Springer, Santa Barbara. pp 181-194

Fang H, Ku Y, Shang T (1996) The integration of modern and traditional Chinese medicine in the treatment of fractures; a simple method of treatment for fractures of the shafts of both forearm bones. Clin orthop 4-11

Freire P (1972) Pedagogy of the oppressed. Penguin Books, Harmondsworth

Gordon C, Waage J (2010) London: United Kingdom Collaborative on Development Sciences (UKCDS)

Green S (1999) Orthopaedic surgeons: inheritors of tradition. Clin Orthop 258-63

Grossman G (1993) Innovation and growth in the global economy. MIT Press, Boston

Hanushek E, Ludger W (2007) The role of education quality in economic growth, world bank policy research working paper, WPS4122, (February), Washington, DC: World Bank

Kisangani E (2005) Development of African administration: pre-colonial times and since. In: Tummala K (ed) Public policy and public administration. EOLSS \& UNESCO, New York

Los B, Timmer M (2003) The appropriate technology explanation of productivity growth differentials: an empirical approach. Groningen Growth and Development Center \& SOM Research School, Groningen

Mkabela Q (2005) Using the afrocentric method in researching indigenous African culture. The Qual Rep 10(1):178-189 
Mkandawire T, Charles S (2003) African voices on structural adjustment program. Council for the Development of Social Sciences Research, Dakar

Mkandawire T, Soludo C (1999) Our continent, our future: African perspectives on structural adjustment. Dakar: Council for the Development of Social Science Research in Africa

Ndah A (2010) Public policy and policy inappropriateness in Africa: causes, consequences and the way forward. Xiamen University, Amoy

Nesta Foundation. (2013, 06 29). Innovation drives economic growth. Retrieved from A Nesta Foundation Web site: http://www.innovationexcellence.com/blog/2013/06/29/innovation-driveseconomic-growth-news-from-nesta/\#sthash.SYf2elRr.dpuf

Nsamenang A (1995) Factors influencing the development of psychology in sub Saharan Africa. Int J Psychol 30(6):729-739

Olokoshi A (2000) Democratization, globalization and effective policy making in Africa. IDRC Books, Canada

Oluba M (2010) Africa's public public policy challenge: why appropriate policies are not adopted. May, 18 2010: Entrepreneur Newspaper

Owusu Y (2012) Organizational culture and public sector reforms in a post-washington consensus era: lessons from ghana's good reformers. Prog Dev Stud 135-151

Rosenberg N (2004) Innovation and economic growth. OECD, Paris

Sarpong P (2002) Peoples differ: an approach to inculturation in evangelization. Sub-Saharan Publishers

Shang T, Dong Y (1987) Treatment of forearm bone fractures by an integration of traditional Chinese and Western medicine. Clin Orthorp 56-64

Trifonas P (2003) Toward a decolonizing pedagogy: social justice reconsidered. In: Trifonas P (ed) Pedagogies of difference: Rethinking education for social change. Routledge, London

UNESCO (2000, March) Best practice on indigenous knowledge. Retrieved from United Nations Education Scientific and Cultural Organization: http://www.unesco.org/most/bpikpub.htm\#role Walker D, Jonas S (1986) Curriculum and aims. Columbia, New York

West J (2000) The Mystery of innovation: aligning the triangle of technology, institutions and organisation. Australi J Manag 26, Special Issue, August, 21-43

Woodman G, Bradford M (1987) How state courts create customary law in Ghana and Nigeria. In: Woodman G, Bradford M (eds) Indigenous law and the state. Fows Publications, Dordrecht (Holland)

World Bank (2000) Indigneous Knowledge Notes. Retrieved from World Bank: http://www. worldbank.org/afr/ik/ikn87.htm

Open Access This chapter is licensed under the terms of the Creative Commons Attribution 4.0 International License (http://creativecommons.org/licenses/by/4.0/), which permits use, sharing, adaptation, distribution and reproduction in any medium or format, as long as you give appropriate credit to the original author(s) and the source, provide a link to the Creative Commons license and indicate if changes were made.

The images or other third party material in this chapter are included in the chapter's Creative Commons license, unless indicated otherwise in a credit line to the material. If material is not included in the chapter's Creative Commons license and your intended use is not permitted by statutory regulation or exceeds the permitted use, you will need to obtain permission directly from the copyright holder. 